\title{
СУТЬ, ВИДЫ И СИСТЕМЫ ЭКОНОМИЧЕСКИХ ЗАКОНОВ
}

\author{
(C) 2021 Щеголихина Вероника Ильинична \\ студент \\ Сибирский Федеральный Университет, Институт Управления Бизнес-процессами \\ E-mail: verasheg1234@gmail.com \\ (c) 2021 Соснина Валерия Алексеевна \\ студент \\ Сибирский Федеральный Университет, Институт Управления Бизнес-процессами \\ E-mail: lera.sosnina.01@mail.ru \\ (c) 2021 Мордвинова Татьяна Григорьевна \\ студент \\ Сибирский Федеральный Университет, Институт Управления Бизнес-процессами \\ E-mail: Tanyacds2000@mail.ru
}

Научный руководитель: Жуков Максим Юрьевич, ассистент кафедры «Экономика и управление бизнес-процессами»

В данной статье рассмотрены фундаментальные понятия и признаки, виды и системы экономических законов. Рассмотренные классификации и подробно описанные основные законы мировой экономики сформируют обобщенное представление механизма взаимодействия различных экономических законов. На основании полученных данных обозначено место и важность соблюдения законов экономики для стабильного развития рынка.

Ключевые слова: Экономика, экономические законы, закон спроса, закон предложения

\section{ВВЕДЕНИЕ}

Экономическая наука, как и любая другая имеет свои закономерности и постоянства. Поэтому она также имеет различные законы, принципы, свойства и тому подобное. Экономика не постоянная наука, она развивается по мере развития общества, и законы не являются исключением.

Экономические законы важная составляющая экономической науки, так как они концентрируют устойчивые, повторяющиеся связи во взаимоотношениях и взаимодействиях между элементами и субъектами экономических процессов. Они постоянно находятся во взаимосвязи друг с другом или влияют и вытекают в новые закономерности по мере развития науки, ее наблюдений и изучений.

Данная тема является актуальной в наши дни тем, что рынок развивается, и его необходимо изучать и исследовать с помощью экономических законов, а также нужно уметь применять эти законы и по необходимости выводить новые.

\section{1. Понятие и признаки экономических} законов

Как и в любой другой сфере жизни общества, в экономике существуют определенные зависимости и закономерности, которые выражаются в различных видах понятий, категорий и законов. Любой закон отражает внутреннюю связь между явлениями и процессами, и экономические не являются исключением.

Экономический закон - объективные, внутренние, существенные, устойчивые, постоянно повторяющиеся причинно-следственные связи в системе производственных отношений [1].

Экономические законы обладают рядом характерных признаков:

- носят объективный характер;

- возникают в результате становления определенных экономических отношений;

- обладает причинно-следственной связью, которая имеет определенный результат (экономический);

- выражает внутренне необходимую взаимосвязь; 
- носят социальный характер.

Экономические законы, в отличие от законов природы имеют исторический характер, и в свою очередь сложились в условиях меняющейся хозяйственной деятельности. Они действуют независимо от воли и сознания людей. Люди не могут их самовольно изменить, отменить или создать, но их ценность на практике является неотъемлемой частью экономических отношений. Так мы можем получить более достоверное и обширное представление об экономике, его развитии, совершенствах и недостатках

Можно выделить еще одну важную особенность экономических законов - их неточность. Это связано с тем, что деятельность людей непредсказуема и не имеет точной закономерности действий, нет такой возможности чтобы сделать точный прогноз на будущее. Деятельность людей, их поступки вызывают некоторые трудности при систематизации, их оценки и структурировании. Тем самым можно сделать вывод о том, что экономические законы имеют такую же приблизительную оценку, как и человеческое поведение, поскольку мы не можем знать о точном поведении людей, имеем расплывчатые закономерности и в экономической сфере.

Таким образом, экономическая теория исследует причинно-следственные взаимосвязи и взаимозависимости, возникающие между людьми в процессе производственных отношений. На этой основе экономические законы можно определить как существенные, прочно остающиеся в экономических процессах и явлениях объективные взаимозависимости и причинноследственные связи, без которых невозможно существование определенных производственных отношений в их целостности и развитии.

\section{2. Виды экономических законов}

Экономические законы, как и экономика, имеет отличительные свойства для разных эпох, экономических систем, государств. В зависимости от различных факторов выделяет несколько групп экономических законов (см. рис. 1). На данный вид классификации влияют также тип собственности производства, характер взаимосвязи между субъектами.

Рассмотрим каждый вид экономических законов поподробнее.

Всеобщие экономические законы - это такие законы, которые характерны для всех без исключения исторических эпох, экономических систем и формаций. К данному виду законов можно отнести: закон возвышения потребностей, закон роста производительности труда, закон экономии времени и др. Всеобщие законы объединяют воедино формирование всех общественно-экономических формаций.

Общие экономические законы - это законы, свойственные, в отличие от всеобщих, для некоторых исторических эпох или экономических формаций. Данный тип законов также может распространяться на некоторые ступени развития общественного производства. Например, закон спроса, закон предложения, закон стоимости и др.

Специфические экономические законы это законы, характерные для одного, конкретного способа производства, присущие для нынешнего общественного строя. Такие законы применяются только в определенной экономической формации. К таким законам относятся, например, закон прибавочной стоимости при капитализме, или основной экономический закон социализма.

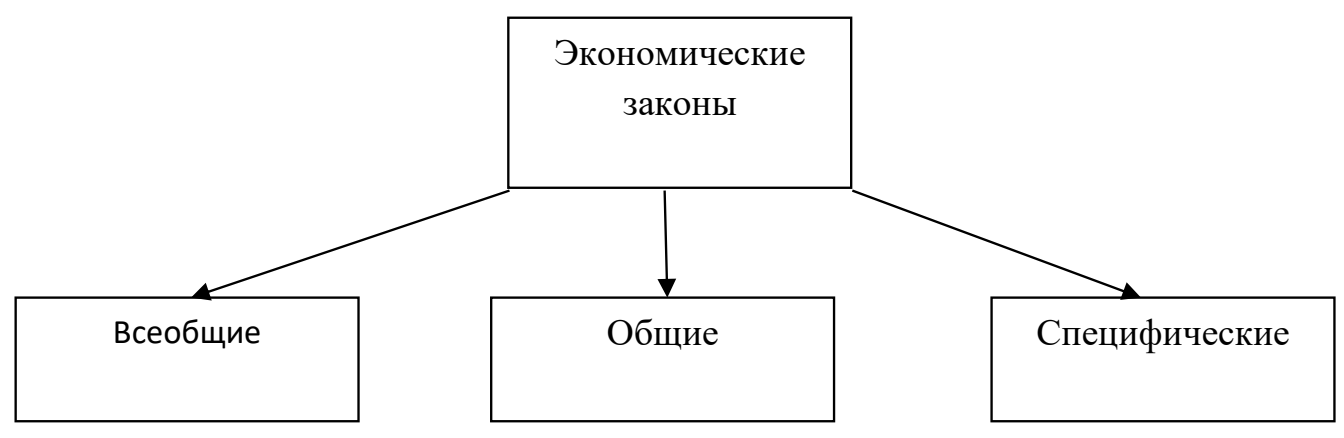

Рисунок 1. Классификация экономических законов 
Выделяют также и другие виды экономических законов:

- стадиальные экономические законы - это законы, которые характерны только для одной стадии способа производства. К такому рода законам относится закон монопольной прибыли, закон планомерности экономического развития и др.;

- фазовые экономические законы - это законы, которые характерны только для определенной фазы способа производства, например, законы потребления.

Все виды экономических законов взаимосвязаны и оказывают влияние друг на друга. Так всеобщие экономические законы отражаются в общих, специальных, стадиальных и фазовых законах. Каждый экономический закон тем или иным образом влияет на другой, взаимодействуя с ним, может оказывать как положительное, содействующие воздействие, так и иметь противоположную направленность.

\section{3. Системы экономических законов}

Система экономических законов включает в себя различные виды, которые были рассмотрены раннее. Системы также делятся с точки зрения связи на:

- координационные связи (горизонтальные) - законы действует равнозначно, без соподчинения, характерно для всего мирового хозяйства, отдельных регионов и стран, отраслей народного хозяйства и т.д.;

- субординационные связи (вертикальные) - другие законы, подчинены основному экономическому закону, характерно для общественно-экономических формаций.

Рассмотрим подробнее некоторые экономические законы.

\section{Закон возвышения потребностей}

Для начала разберемся, что такое потребности.

Возникающая нужда людей, для поддержания жизнедеятельности и развития организма, выраженная в определенных благах, товарах и услугах называется потребностью.

Разнообразие потребностей людей неограниченно, так как включает не только физиологические и индивидуальные нужды, но также и социальные: семьи, государства, всего общества.

Число видов благ, в которых люди испытывают потребность, исчисляется миллионами, но это число с каждым десятилетием меняется в большую сторону. Также меняется не только количество потребностей, но и их качество с развитием производства, структура, соотношение между видами потребностей. Такой феномен получил название закон возвышения потребностей.

Закон возвышения потребностей - это экономический закон, выражающий необходимость качественного и количественного роста и совершенствования потребностей людей в соответствии с развитием производства и культуры [2].

Применение слова «возвышение» взамен напрашивающихся слов «увеличение», «рост» призвано подчеркнуть, что имеется в виду не только стремление к количественному возрастанию потребления, однако вне меньшей степени преобразование структуры потребностей, расширение их круга, разнообразия, смещение приоритетов, развитие взаимозаменяемости, качественное совершенствование. Во многих случаях изменение потребностей объективно обусловлено переменами в условиях жизни, в среде, окружающей людей. Стремление к увеличению продолжительности жизни, снижению заболеваемости, духовному совершенствованию, самовыражению личности, личной и общественной безопасности также служит объективным фактором расширения круга потребностей.

Таким образом, прогресс человечества, рост его культуры, знаний, преобладание духовных начал, расширяющиеся возможности экономики неизбежно обуславливают возвышение потребностей как закономерность человеческой цивилизации.

\section{Закон спроса}

Спрос - это зависимость между ценой и количеством товара, который покупатели могут и желают купить по строго определенной цене, в определенный промежуток времени, а также потребность, не только подтвержденная деньгами, но и «выведенная» на рынок [3].

Существует также такое понятие как полный спрос, которое означает совокупность спроса на конкретный товар по различным ценам, а количество товара, которое потребитель имеет возможность и готов купить по установленной цене, называется величиной (объемом) спроса.

Спрос имеет функциональную зависимость величины спроса от цены, отсюда вытекает закон спроса.

Закон спроса показывает, что при измене- 
нии цены, при прочих равных условиях спрос на товары в количественном выражении изменяется в обратной зависимости.

Такую зависимость изменения количества приобретенных благ по разным ценам описывает кривая спроса (см. рис. 2).

Индивидуальная кривая спроса может отличаться у разных потребителей, в зависимости от личных предпочтений и бюджетных ограничений.

Как уже говорилось, на формирование спроса влияют цена на приобретаемые блага, так называемый ценовой детерминант, на графике движение вдоль линии кривой спроса.

На изменение кривой спроса влияет не только цена (ценовой детерминант), но и неценовые детерминанты, которые включают в себя [3]:

- личные предпочтения потребителей: потребности, вкус (сезонность, мода, образ жизни и деятельности);

- доход, его изменение производит на спрос различный эффект, либо спрос повышается, либо уменьшается, но есть и нейтральные товары, которые потребители покупает вне зависимости от своего бюджета, так как это объясняется их физиологическими особенностями (многие продукты питания);

- цены на сопряженные товары, которые делятся на взаимозаменяемые и взаимодополняемые, при изменении цены на одни товары, спрос уменьшится или увеличится на другие.

Не всегда спрос соответствует его закону, есть исключения из этого правила, и тогда спрос формируется другими критериями.

1. Эффект ожидаемой динамики цен.

Происходит формирование ажиотажного спроса - спроса, который имеет уровень сверхнормы, порожденный ожидаемым повышение цен или исчезновением товара (см. рис. 3).

2. Эффект «цена - показатель качества».

Спрос людей переключается на более дорогостоящие товары, оправдывая это тем, что хо-

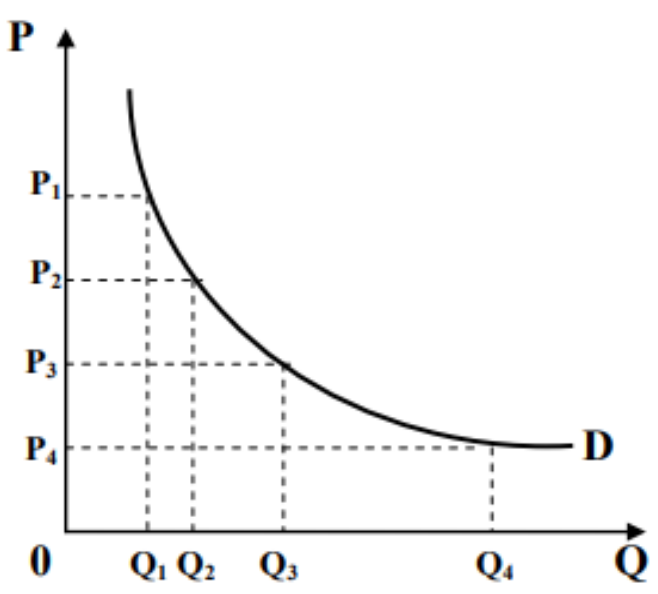

Рисунок 2. Кривая индивидуального спроса

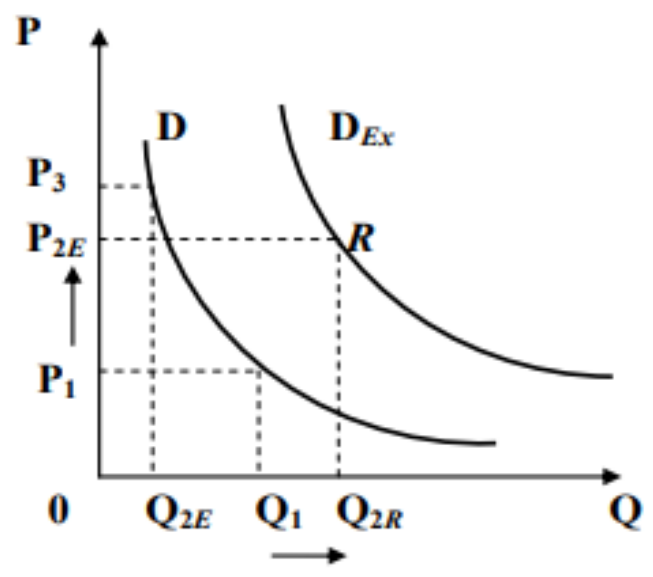

Рисунок 3. Эффект ожидаемой динамики цен 
тят получить больший эффект от качества. Цена становится фактором изменения кривой спроса, но не в характерном для нее порядке.

Парадоксы закона спроса. Как правило, чем выше цена, тем ниже величина спроса, и наоборот, но в некоторых случаях отмечается так называемый парадоксальный спрос - повышение величины спроса с ростом цены. Это характерно для людей, цель, которых является демонстрация своего престижного потребления (дорогая одежда, автомобили, ювелирные украшения и т.д.)

Эффект престижного спроса, называется также эффектом Веблена. Здесь также выделяют два эффекта людей:

- сноб - человек, который хочет подчеркнуть свою исключительность, тем самым сокращая спрос на товар, для людей с таким же предпочтением;

- присоединение к большинству - относится к той группе людей, которая стремится не к уникальности, а подражанию, тем самым увеличивая спрос.

Рассмотрим эффект Веблена на рисунке 4.

Существует также эффект Гиффена, который имеет обратную зависимость.

\section{Закон предложения}

Сначала рассмотрим, что такое предложение. Желание и готовность продавцов продать определенный товар по конкретной цене называется предложением. Количество этого товары выражается величиной предложения.

Закон предложения - закон, в соответствии с которым при увеличении цены на товар предложение этого товара повышается при прочих неизменных факторах [3]. Имеется зависимость обратная закону спроса.

Зависимость величины предложения от цены можно представить на графике предложения, которую можно описать с помощью кривой предложения, линии, на которой каждой величине предложения соответствует определенная цена. Может быть представлена в виде прямой линии, но на практике чаще в виде гиперболы (см. рис. 5).

Так же, как и спрос, предложение имеет как ценовые, так и неценовые детерминанты, которые влияют на движение кривой влево или вправо. Например, [3]:

- цены на ресурсы - при увеличении их цены, увеличивается стоимость и товара, а, следовательно, повыситься цена на данный товар;

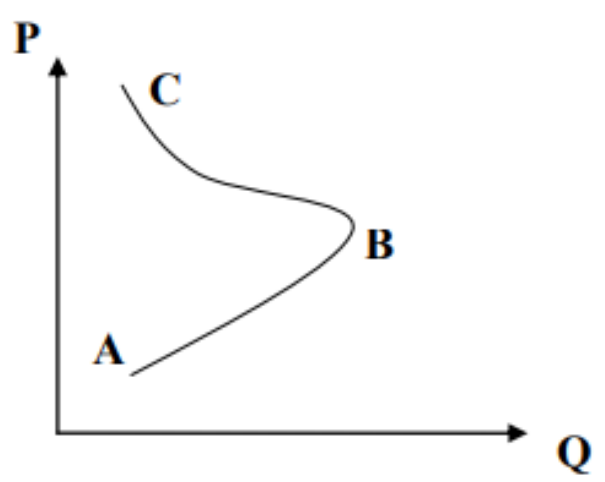

Рисунок 4. Эффект Веблена
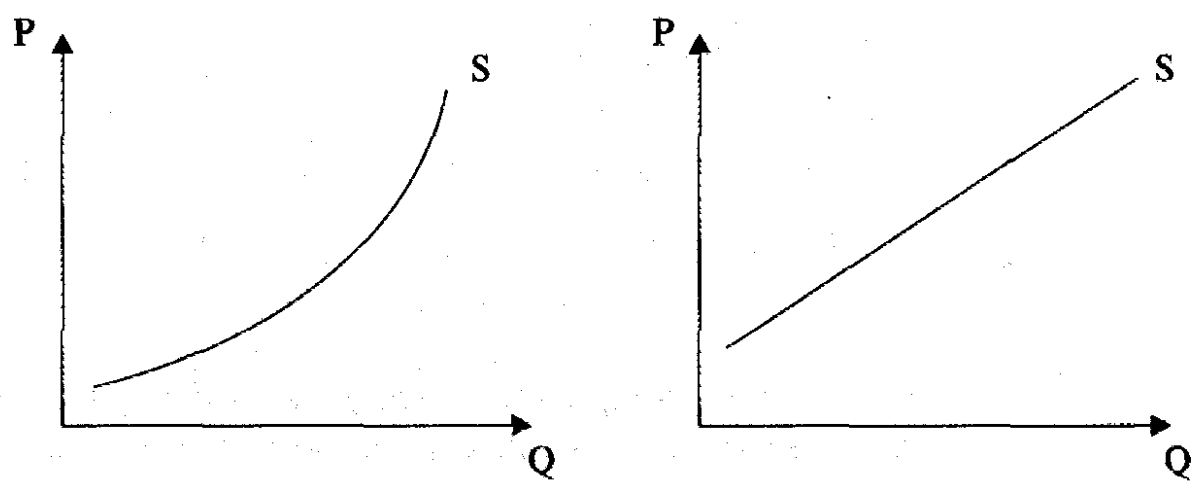

Рисунок 5. График предложения 
- уровень технологий - имеет такой же эффект как и цены на ресурсы, следовательно предложение увеличится;

- величина налогов - производителям приходится повышать цену на товары, чтобы компенсировать рост налогов, особенно это применяется на практике для высокооблагаемых товаров;

- ожидание роста цен - продавцы, ожидая роста цен и затрат сокращают текущее предложение.

На рисунке 6 показано как изменяется предложение под воздействием на него различных неценовых детерминантов.

\section{ЗАКЛЮЧЕНИЕ}

Рассмотрев, понятие, принципы и сущность экономических законов, можно сделать вывод о том, что они являются неотъемлемой частью экономической системы.

Они определяют упорядоченное развитие экономики, действуют во взаимодействии и с другими факторами и науками.

Их особенность заключается в том, что игнорирование или их опровержение может принести крайне негативный результат для всей экономики в целом, к примеру, кризис, инфляция, все эти явления также происходят, в том числе и по этой причине.

Экономическая наука, как и любая другая, постоянно развивается, расширяется и уточняется, это может позволить еще более прочное и точное ее регулирование, чтобы как можно быстрее и качественнее предотвращать различные негативные проявления. Законы нужно также уметь выявлять и применять не только в теории, но и качественно на практике.

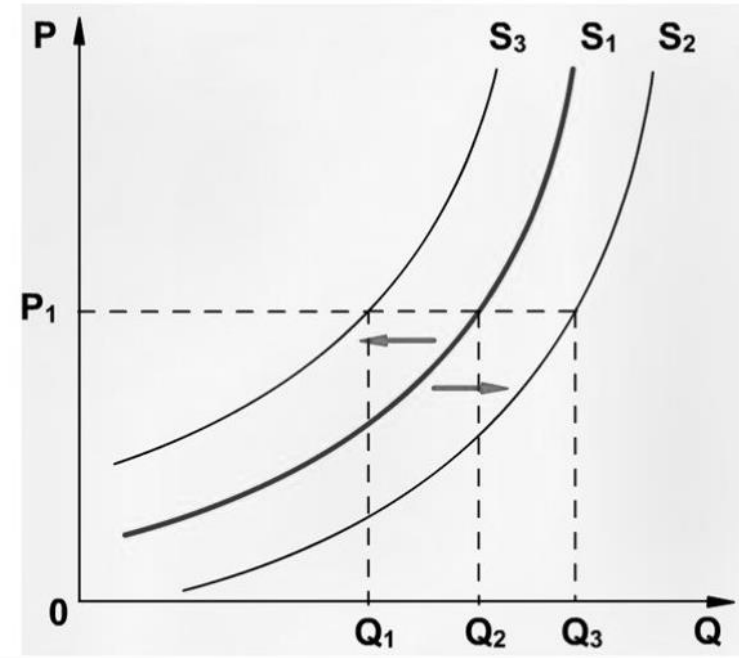

Рисунок 6. График изменения предложения

\section{Библиографический список}

1. Общая экономическая теория: учебник для студентов высших учебных заведений [Электронный ресурс]: электронное учебное издание / В.А. Сидоров, Е. Л.Кузнецова // Майкоп: ООО «ЭлИТ», 2017. - Режим доступа: http://201824.selcdn.ru/elit-050/index.html.

2. Дерен, В. И. Экономика: экономическая теория и экономическая политика в 2 ч. Часть 1 : учебник и практикум для вузов / В. И. Дерен. - 6-е изд., испр. и доп. - Москва: Издательство Юрайт, 2019. - 432 с. - Режим доступа: https://urait.ru/bcode/444492.

3. Куприн, А.А. и др. Экономика [Электронный ресурс]: учебное пособие / А. В. Буга, И. И. Грозаву, Т. В. Данилова, Л. В.Дорофеева, В.С. Кудряшов, А. А. Куприн, А.Д.Шматко; под ред. А.А. Куприна; Сосновоборский филиал РАНХиГС. - СПб.: Астерион, 2018. - 456 с.

4. Лобачева, Е. Н. Экономическая теория [Электронный ресурс]: учебник для вузов / Е. Н. Лобачева [и др.]; под редакцией Е. Н. Лобачевой. - 4-е изд., перераб. и доп. - Москва: Издательство Юрайт, 2019. - 501 с. - Режим доступа: https://urait.ru/bcode/431309.

5. Сукиасян, Н.Г. Экономические законы как правовая основа форм и методов финансовой деятельности государства / Н. Г. Сукиасян // БГЖ. -2016. - № 1 (14). - С. 208-214. 